\title{
Genomic futures of prenatal screening: ethical reflection
}

Citation for published version (APA):

Dondorp, W. J., Page-Christiaens, G. C., \& de Wert, G. M. W. R. (2016). Genomic futures of prenatal screening: ethical reflection. Clinical Genetics, 89(5), 531-538. https://doi.org/10.1111/cge.12640

Document status and date:

Published: 01/05/2016

DOI:

$10.1111 /$ cge. 12640

Document Version:

Publisher's PDF, also known as Version of record

Document license:

Taverne

Please check the document version of this publication:

- A submitted manuscript is the version of the article upon submission and before peer-review. There can be important differences between the submitted version and the official published version of record.

People interested in the research are advised to contact the author for the final version of the publication, or visit the DOI to the publisher's website.

- The final author version and the galley proof are versions of the publication after peer review.

- The final published version features the final layout of the paper including the volume, issue and page numbers.

Link to publication

\footnotetext{
General rights rights.

- You may freely distribute the URL identifying the publication in the public portal. please follow below link for the End User Agreement:

www.umlib.nl/taverne-license

Take down policy

If you believe that this document breaches copyright please contact us at:

repository@maastrichtuniversity.nl

providing details and we will investigate your claim.
}

Copyright and moral rights for the publications made accessible in the public portal are retained by the authors and/or other copyright owners and it is a condition of accessing publications that users recognise and abide by the legal requirements associated with these

- Users may download and print one copy of any publication from the public portal for the purpose of private study or research.

- You may not further distribute the material or use it for any profit-making activity or commercial gain

If the publication is distributed under the terms of Article $25 \mathrm{fa}$ of the Dutch Copyright Act, indicated by the "Taverne" license above, 


\section{Review}

\section{Genomic futures of prenatal screening: ethical reflection}

Dondorp W.J., Page-Christiaens G.C.M.L., de Wert G.M.W.R. Genomic futures of prenatal screening: ethical reflection. Clin Genet 2016: 89: 531-538. @ John Wiley \& Sons A/S. Published by John Wiley \& Sons Ltd, 2015

The practice of prenatal screening is undergoing important changes as a result of the introduction of genomic testing technologies at different stages of the screening trajectory. It is expected that eventually it will become possible to routinely obtain a comprehensive 'genome scan' of all fetuses. Although this will still take several years, there are clear continuities between present developments and this future scenario. As this review shows, behind the still limited scope of screening for common aneuploidies, a rapid widening of the range of conditions tested for is already taking shape at the invasive testing stage. But the continuities are not just technical; they are also ethical. If screening for Down's syndrome is a matter of providing autonomous reproductive choice, then why would providing the choice to have a full fetal genome scan be something entirely different? There is a clear need for a sustainable normative framework that will have to answer three challenges: the indeterminateness of the autonomy paradigm, the need to acknowledge the future child as an interested stakeholder, and the prospect of broad-scope genomic prenatal screening with a double purpose: autonomy and prevention.

\section{W.J. Dondorpa , G.C.M.L. Page-Christiaens ${ }^{b}$ and G.M.W.R de Wert ${ }^{\mathrm{c}}$}

\author{
aDepartment of Health, Ethics and \\ Society, Research Schools GROW, \\ CAPHRI, Maastricht University, \\ Maastricht, The Netherlands, bWilhelmina \\ Children's Hospital Birth Centre, Utrecht \\ University Medical Centre, Utrecht, The \\ Netherlands, and ${ }^{\mathrm{C}}$ Department of Health, \\ Ethics and Society, Research Schools \\ GROW, CAPHRI, Maastricht University, \\ Maastricht, The Netherlands \\ Key words: ethics - NIPT - microarray \\ - prenatal screening - whole genome \\ sequencing \\ Corresponding author: W. J. Dondorp, \\ Department of Health, Ethics and \\ Society, Research Schools GROW, \\ CAPHRI, Maastricht University, PO Box \\ 616, Maastricht, $6200 \mathrm{MD}$, The \\ Netherlands. \\ Tel.: +43611184355; \\ fax: +433884171 ; \\ e-mail: \\ w.dondorp@maastrichtuniversity.nl
}

Received 1 May 2015, revised and accepted for publication 7 July 2015
It may seem that apart from better tests every decade or so, prenatal screening for fetal abnormalities has not changed much since its introduction in the last quarter of the past century. However, behind the scenes, the contours of a revolution are taking shape. The two main ingredients for this are already present, although still at distinct stages of the screening trajectory: the use of cell-free DNA (cfDNA) from maternal plasma for non-invasive testing for common aneuploidies and the use of high-resolution genomic technologies at the follow-up stage. As there is proof of principle that the whole fetal genome can be sequenced from cfDNA, the fusing of these developments into a scenario of non-invasive comprehensive genomic screening seems only a matter of time. In this ethics-oriented review, we show that this prospect challenges the normative framework that over the past decades has been developed for prenatal screening for fetal abnormalities. Interestingly, much of the contours of the future of the practice (broad-scope, undirected, multipurpose screening) can already be discerned in routine prenatal ultrasound, an instance of prenatal screening that to some extent has always defied this framework.

The set-up of this review is as follows. First, we will discuss the reasoning behind the normative framework: the set of aims and principles and norms that together provide ethical guidance to the current practice of prenatal screening. Second, we will give a background sketch of current practice (genomic as well as ultrasound screening) and developments. The next three sections are about ethical issues arising at distinct stages in the revolution starting with non-invasive prenatal testing (NIPT) and potentially leading to some form of broad-scope fetal genome scanning in the midterm future. 


\section{Normative framework}

In general medical discourse, 'screening' refers to the use of a specific type of test: a test that does not provide a final diagnosis. In health policy discourse, by contrast, the distinguishing characteristic of 'screening' is that medical tests of whatever nature are systematically offered on the initiative of medical or public health professionals to an as-yet unburdened population (1). In this review, we will use the term 'screening' in this wider practice-oriented understanding of the term, unless indicated otherwise. Screening in this sense can take the form of large-scale population screening programmes set up by public health authorities, but may also consist of routine test offers by individual practitioners.

As screening in this sense is an unrequested offer, there should be evidence that the potential benefits outweigh the risk of harms that screening always also entails. The normative framework for responsible screening, as initially developed in the 1960s by Wilson \& Jungner and refined and adapted ever since $(1,2)$, insists that not only should there be a suitable test (in terms of clinical validity and predictive value) but also that the early detection of the targeted conditions should have a clear clinical utility, mostly understood in terms of opportunities for treatment or prevention. Participation in screening should be voluntary and those to whom screening is offered should be assisted in making an informed decision. Moreover, where screening is paid for from public funds, the target condition should be an important health problem and funding requires justification in the context of total health care spending.

From a normative perspective, there are two main types of prenatal screening: (i) screening for conditions (e.g. infectious diseases, blood group sensitization, etc.) that may lead to an unfavorable pregnancy outcome and where early detection enables timely treatment or prevention and (ii) screening for fetal abnormalities (such as Down's syndrome) where early detection allows for no other options but the choice either to prepare for a child with a serious handicap or health problem or to request termination of pregnancy. The former of these two types makes an ethically unproblematic fit with the general screening framework's requirement of clinical utility. But what is the utility of prenatal screening for untreatable conditions such as Down's syndrome? Some have suggested that there is not really a difference here $(3,4)$. For instance, in the early days of setting up prenatal screening programmes, Stein et al. argued that it was desirable from a public health perspective to aim for an 'almost total prevention of Down's syndrome (...) by screening all pregnant women' (5). This 'prevention' account of the clinical utility of prenatal screening has led to strong moral criticism (6). The objections are twofold. First, turning selective abortion into a public health tool may lead to women being subtly pressured into making the 'right' decisions. This would be at odds with respecting abortion decisions as morally sensitive and ultimately personal choices (2). Second, according to what is known as the 'disability rights' or 'expressivist critique', prenatal screening sends a discriminatory message about the worth of the lives of people living with the relevant conditions (7). In order to avoid these moral challenges, official accounts provide a different reading of what prenatal screening is about. Internationally, government documents and websites of public health authorities (such as e.g. the British National Screening Committee) state that the aim of screening for fetal abnormalities is to enable autonomous reproductive decision making by individual women or couples. Although this has not silenced the discussion about the acceptability of prenatal screening [with some commentators arguing that individual choices invited by the screening offer may still be seen as 'eugenic' $(8,9)]$, the 'autonomy paradigm' is at the core of a widely shared consensus that prenatal screening serves a morally acceptable aim.

Clearly, if this is to be more than window dressing, it requires practices that reflect this atypical aim (autonomy rather than prevention) in every aspect of how the screening is presented, offered, carried out, and evaluated (6). For instance, it means that information and counseling should as much as possible be non-directive and aimed at assisting women in making an 'informed choice' (10). Moreover, the autonomy aim can only be meaningfully upheld in a society where adequate levels of care are available for people with the relevant conditions and where those who choose to have a child with special needs are not held responsible for imposing a burden on society (11).

\section{Current practice and developments}

In the past decades, the practice of prenatal screening for genomic abnormalities has changed only slightly. The focus was mainly on Down's syndrome (trisomy 21) and other common aneuploidies (trisomy 13 and 18) were added later. Countries with formal screening programmes for these conditions use a two-tiered approach. The first line test (combined first trimester screening; cFTS) consists of biochemical markers in maternal blood combined with an ultrasound assessment of the fetal nuchal translucency (NT) at 11-14 weeks. Women with a risk above a cut-off of e.g. 1:150 or 1:200, or with an enlarged NT, are offered a diagnostic test (karyotyping or molecular genotyping) in chorionic villi or amniotic fluid cells, obtained by invasive means. At a false-positive rate of 5\%, cFTS-based screening is reported to detect $82-87 \%$ cases of trisomy 21 (12). In most countries, pregnant women are also offered a routine ultrasound 'fetal anomaly scan' in the second trimester (between 18 and 21 weeks). The main focus is on major structural anomalies, the finding of which may require early postnatal intervention, allow prenatal treatment or be a reason for the woman to ask for termination of pregnancy (13). Routine ultrasound may also detect minor abnormalities, including small and often transient structural changes (soft markers) that are associated with a higher risk of aneuploidies.

Recent years have seen some important developments. One is the introduction of NIPT either as a secondor first-tier screening test for common aneuploidies. NIPT is based on (different approaches to) sequencing 
of cfDNA in maternal blood, about $10 \%$ of which is of placental origin $(14,15)$. As a test for common aneuploidies, NIPT has much better test characteristics than cFTS, not just in populations with a moderate or high a priori risk for the tested conditions but also in a general risk population. In the recent large-scale prospective NEXT study, all trisomy 21 cases were detected at a false-positive rate of $0.06 \%$ (16). However, the positive predictive value of NIPT ( $80.9 \%$ in the same study) for this condition, although much better than that of cFTS $(3.4 \%, 16)$, is not high enough for considering a positive NIPT result a final diagnosis. In many cases, this has a biological cause including confined placental mosaicism or an undetected vanishing twin (15). The main benefit of NIPT is that because of its much lower false-positive rate, the need for invasive follow-up procedures can be massively reduced as compared with cFTS. As these procedures entail a miscarriage risk (often estimated at around $0.5-1 \%$ ), this also makes prenatal screening considerably safer and hence less harmful (17). In several countries, individual practices have started offering commercially available NIPT as a further option next to existing prenatal screening tests, initially only to women at a known moderate or high risk, but more recently also as an alternative first-tier screening test to a general risk population, very often at the request of pregnant women themselves. This scenario has the further advantage of reducing the number of false negatives and providing early (and highly reliable) reassurance to women receiving a favorable result. However, as long as NIPT is still considerably more costly than cFTS, financial barriers stand in the way of implementing NIPT as a first-tier test in countries where prenatal screening is offered as a public health service.

A second development is the introduction of chromosome microarray (CMA) in prenatal follow-up testing, especially but not exclusively after detection of enlarged NT or other ultrasound abnormalities. CMA is based on either comparative genomic hybridization $(\mathrm{CGH})$ or single nucleotide polymorphism (SNP) analysis and allows targeted or genome-wide testing for copy number variants $(\mathrm{CNVs})$ that cannot be seen with conventional karyotyping (18). This gives a higher yield of clinically relevant abnormalities, including microdeletion and microduplication syndromes. Genome-wide CMA may also lead to findings of clinical significance not related to the ultrasound abnormalities that prompted further testing, or to variants considered benign or of unclear clinical significance $(19,20)$.

\section{Ethics of current prenatal screening practices}

With the better test characteristics of NIPT, prenatal screening for fetal abnormalities can better achieve its aim. As research among pregnant women suggests, a more robust test renders prenatal screening more acceptable for more women, including for those who would regard a positive result as sufficiently informative to prepare themselves for the birth of a child with special needs (21). However, it is also feared that precisely the greater accuracy and safety of NIPT-based prenatal screening may lead to it being presented and regarded as a routine procedure, rather than as an option that well-informed women may either accept or decline (22, 23). Specific ethical issues emerge in debates related to the scope of testing with NIPT (24). These include the clinical importance of a possibly lower yield of findings beyond common aneuploidies as compared to screening with cFTS followed by fetal genotyping in case of a high-risk result $(25,26)$, the best way to deal with additional findings of NIPT itself (27), and whether or not to take the step to expand NIPT-based screening to include sex chromosomal (28) and submicroscopic chromosome abnormalities $(29,30)$.

Routine prenatal ultrasound differs from screening for common aneuploidies in not being targeted to a limited number of serious and non-treatable abnormalities. It is a form of undirected screening, detecting a broad range of abnormalities ranging from serious and non-treatable to milder conditions and conditions that allow for prenatal or postnatal intervention. This makes for an uneasy fit with the normative frameworks summarized earlier. First, the criteria of the general Wilson \& Jungner framework presuppose screening being directed at specific and well-defined disorders. The reason for this is that the balance of benefits and harms of undirected screening is more difficult to define. However, the nature of the technology implies that everything that can be seen on an ultrasound scan will be seen. Second, routine ultrasound cannot be exclusively attributed to either one of the two main types of prenatal screening, as it is a test for both untreatable fetal anomalies and conditions relevant to improving pregnancy outcomes for mother and child. Third, the broad scope of possible findings makes adequate pretest information and counseling for routine ultrasound an important challenge.

It is perhaps remarkable that the obvious tensions between routine ultrasound and the autonomy paradigm have not led to much ethical debate. Part of the explanation may be that routine ultrasound is more than only a screening test. For professionals, it is also a pregnancy monitoring tool, whereas pregnant women value the scan as a first opportunity to 'see the baby'. This may have contributed to routine ultrasound being regarded more as an 'exception confirming the rule' than as a real challenge to the autonomy paradigm.

\section{Follow-up testing as a gray area between diagnosis and screening}

Invasive follow-up testing after a positive initial screening test (cFTS, NT, NIPT, or routine ultrasound) can be understood in two different ways. First, it is clinical diagnostic testing that should as far as possible be targeted to finding a diagnosis explaining the abnormal test result. Second, in addition to finding a diagnosis, invasive follow-up testing provides an ideal opportunity for further screening by also looking for abnormalities that cannot (yet) be screened for with non-invasive means. As we will show, these different views can be traced in several contemporary debates about the scope of follow-up 


\section{Genomic futures of prenatal screening}

testing, with the latter view fueling the thrust toward an ever-wider testing.

Some years ago, it was discussed whether in pregnancies with a positive cFTS (but without abnormal ultrasound findings) or at a higher risk for fetal aneuploidy because of maternal age, karyotyping should be replaced by the then new Rapid Aneuploidy Diagnostic (RAD) test, such as quantitative fluorescent-polymerase chain reaction (QF-PCR) (31). The argument for doing so was that while karyotyping inevitably leads to incidental findings (other chromosomal abnormalities than the common aneuploidies tested for at the screening stage), RAD allows to largely avoid this, thus also avoiding the difficult counseling and decision making associated with karyotypes of unclear prognosis. The maxim behind this approach has been summarized as 'test what you screen for' (32). The prevailing view, however, is that this denies prospective parents relevant information about abnormalities with potential clinical significance that they might consider a reason for abortion (33).

More recently, the debate has shifted to whether new molecular technologies should be used to look for more rather than less than can be found with traditional karyotyping (31). There seems to be a growing support for the position that microarrays should not be limited to pregnancies with ultrasound abnormalities (see below), but be used to maximize the yield of invasive testing also in pregnancies with an elevated aneuploidy risk (based on abnormal cFTS/NIPT results or on maternal age), but without ultrasound abnormalities. Pointing to the about $1 \%$ more clinically relevant findings in this population as compared to traditional karyotyping, the authors of a recent review state that 'on a population level, this represents a large number of cases where clinically relevant copy number changes will go undetected if microarray technology is applied only to fetuses with an abnormal ultrasound'. They suggest that 'once the invasive procedure has been carried out then microarray should be the frontline test once aneuploidies have been excluded by other methodologies (e.g. QF-PCR)' (34). These quotes are revealing: instead of considering a normal RAD result as completing the screening trajectory in fetuses with normal anatomy, the idea is that this should be a starting point for further screening. The fact that invasive testing risks have already been considered is presented both as an opportunity and a justification to look beyond common aneuploidies.

In pregnancies with first or second trimester ultrasound abnormalities, the use of microarrays instead of karyotyping is an accepted practice (35). But there is much debate about microarray design, in terms of coverage of genomic regions (targeted or genome-wide arrays) and resolution (36), as well as about policies for reporting secondary findings and findings of uncertain significance $(35,37)$. Here again, it can be asked how the use of this technology as a follow-up to screening should be understood: is it (only) aimed at obtaining a diagnosis that explains the ultrasound abnormality or (also) at screening for further abnormalities not related to that finding? (38). But things are different here from confirmatory testing after aneuploidy screening in two respects. First, when finding an explanation for an abnormal ultrasound, it may not be clear where in the genome to look for the cause of the (often syndromic) problem (or problems). This may require broad-scope testing for what is still a diagnostic purpose, very similar to how in the postnatal setting, microarrays or more recently also whole-exome sequencing is used to find a genetic diagnosis in patients presenting with complex phenotypes. As is also the case in the postnatal setting, this makes it difficult to draw a firm line not only between what is still diagnosis and what should be regarded as additional screening but also between what is still clinical testing and what should be regarded as research (38). Second, unlike after aneuploidy screening, 'looking for more' at follow-up is continuous with the scope of the preceding screening step. Given that routine ultrasound already screens for whatever can be found that is clinically relevant, looking beyond an explanation for a specific ultrasound abnormality does not seem to amount to doing something different.

In sum, the thrust of these debates and developments is toward wider testing at the follow-up stage, partly reflecting the fact that targeted testing may not always suffice to find a diagnosis, but partly also as a deliberate move to use what is formally diagnosis as a platform for broad-scope screening for clinically relevant abnormalities that would otherwise go undetected. Although this may as well be driven by scientific interests, the implicit justification seems that not using the opportunity to find more abnormalities rather than less amounts to providing suboptimal care to women who have already agreed to prenatal testing.

From an ethical point of view, the following considerations are relevant. First, 'changing the game' from diagnostic testing to screening requires explicit informed consent (39). Ideally, possible options to broaden follow-up testing into further screening should be briefly discussed prior to aneuploidy or ultrasound screening, in order to avoid women being drawn into what they may experience as a screening trap. Even if most pregnant women do indeed want to know about other clinically relevant abnormalities and appreciate the benefits of further screening (40), it does not follow that individual women need not be asked about their preferences in this regard (41).

Second, the large majority of women who do not undergo invasive testing are de facto excluded from access to this further round of screening. It is expected that time will close this gap between screening at the pre- and post-invasive testing stages as a result of further improvement and validation of NIPT as a test for clinically relevant abnormalities beyond common aneuploidies (28). For the time being, however, the opportunistic character of further screening at the follow-up stage creates a differential access issue. Although this need not be unacceptable, ideally all pregnant women should be allowed to benefit from the same screening offer (42).

Finally, it seems a logical next step to use next-generation sequencing (NGS) for comprehensive genome scanning in all fetuses that undergo invasive prenatal testing, as soon as doing so is technically, 
logistically, and financially feasible. This will make it possible to test the fetus for an even wider array of genetic conditions and risk factors. And given proof of principle regarding the analysis of the entire fetal genome in maternal plasma $(43,44)$, it is to be expected that this will not remain confined to the invasive testing stage. Clearly, there is no good reason why prenatal genetic screening should remain limited to Down's syndrome or to the three common trisomies. And indeed, ultrasound is already a much wider form of screening. However, is the fact that we can soon test the fetus 'for everything', including for later onset disorders and risk factors for common diseases, a sufficient reason for doing so? If the dynamics of the field is not to be determined by the 'technological imperative', a debate about the scope of prenatal screening is urgently needed $(45,46)$.

\section{Broad-scope genomic prenatal screening and the normative framework}

What then should the scope of future prenatal screening be? Surprisingly, the normative framework does not help answer this question. Or perhaps this is not surprising at all, as the framework was designed to answer different challenges than those arising with broad-scope genomic screening. We identify three main problems with the current framework: the indeterminateness of the autonomy paradigm (see section below), its blindness for the autonomy rights of the future child (see section below), and the need to adapt to the reality of irreducible double purpose screening (see section below).

\section{All about choice?}

In the debate about the scope of testing and reporting policies at the follow-up stage, a powerful trump card is that many pregnant women want to know 'as much as possible', including about non-actionable late-onset conditions and information with uncertain implications $(40,47)$, and that taking autonomy seriously entails providing this information to those who might want it. 'If it is all about choice, then, no option or information potentially relevant to a woman's choice and her decision-making processes should be withheld' (37). The quote is revealing of what seems the dominant interpretation of the autonomy paradigm as currently understood in the field: that it is about maximizing unqualified reproductive choice.

However, as has been pointed out by several commentators $(6,9,11)$, 'pure reproductive autonomy', in the sense of enabling prospective parents to make whatever reproductive choices they find important, cannot be the aim of a screening programme offered and funded as a public health service. Wilkinson uses the example of sex selection to make this point (9). But of course, 'pure autonomy' was not envisaged at the time of those earlier prevention- $v s$-autonomy debates. At that time, 'enabling autonomous choice' had the much more limited meaning of allowing pregnant women and their partners to decide for themselves whether or not they wanted a test for Down's syndrome (and perhaps a very small number of other conditions). As the scope was fixed and as this determined the range of possible choices, this was not 'pure' but qualified autonomy. The aim was to provide autonomous choices related to the possible birth of a child with a serious disorder, where 'serious' should be understood in terms of consequences for the well-being not only of the child but also of the parents and the family as a whole (11). The reason why such qualifications remained largely implicit in the past decades is that with the still limited scope of prenatal screening, there was no need to spell out further criteria. Now that this has changed, some have argued that instead of upholding what seems an incoherent aim, we should normalize prenatal screening by biting the bullet and accept that at least one of its goals is to bring down the birth prevalence of disorders with a high burden of disease, not just for the parents but also for the society (9). The alternative is to see if and how the autonomy paradigm can indeed be qualified in a way that would allow it to meaningfully determine the clinical utility of prenatal screening as a public health service (46). This would have to refer to individual choices recognized as important enough to qualify as a public health issue.

Of course, prenatal screening need not be offered and funded as a public health service. In many countries, but in quite some others, it is an offer available to paying clients of individual practitioners or practices. Some have argued that precisely if we want to take the criticism seriously that any offer of prenatal screening for specific disorders or abnormalities is implicitly directive and sends a discriminatory message, the only acceptable alternative is to move the practice outside the realm of public health to the private sector, where screening can be offered without restrictions $(48,49)$. However, this position comes at a moral price as it creates inequality between those who can and cannot afford to pay for screening.

A more general problem with a maximizing interpretation of the autonomy paradigm arises regardless of whether screening is offered in a public health or a private care setting. The idea of giving women an 'individualized choice' to opt for a maximum of genomic information if that is what they want (40) will lead to information overload and thus paradoxically undermine rather than serve or enhance reproductive autonomy $(50,51)$. In related debates about the use of NGS in postnatal health care and research, it has been proposed as a possible solution for this problem to give pretest information a more general character that would avoid information overload by presenting general categories or types of possible outcomes, differentiated in view of their implications for health and well-being (52). Ideally, this would also allow those tested to decide prior to testing about which outcomes they do and do not want to be informed (42). However, there is still a clear need to test such alternative models of informed consent in empirical studies in different settings. From an ethical point of view, the main question remains how informed (or uninformed) such 'generic consent' would be. 
Genomic futures of prenatal screening

Broad-scope prenatal screening and the interests of the future child

Broad-scope prenatal screening brings a new stakeholder on the stage: the future person, whose interests in being protected against psychosocial and informational harm have not until now played a role in the ethics of prenatal screening $(42,53)$. It is time for this to change, given that broad-scope prenatal screening will also lead to information that (if not used for an abortion) may have a negative benefit-to-harm ratio for the child.

With regard to high-penetrance mutations for later onset disorders, several current guidelines maintain that testing children from affected families for such conditions is problematic unless there are effective treatments or opportunities for prevention that have to be started during childhood $(54,55)$. The concern is that such testing will do the child more harm than good, while also foreclosing his or her right to choose at a later age between knowing and not knowing. Using a term coined by the American philosopher Feinberg, this has been referred to as a possible violation of the child's 'right to an open future' (56). This is an ethical concept expressing the intuition that respect for children as future persons requires safeguarding their future autonomy (57). Some have argued that the 'best interests of the child' is the more appropriate moral currency here, as it includes but is not limited to the child's autonomy interests (58). Either way, the concern behind those guidelines has been taken up in debates about the scope of NGS-based prenatal and neonatal screening as well $(45,59-61)$.

On the same line of reasoning, the balance of benefits and harms related to other possible outcomes of broad-scope screening (including phenotypically mild conditions, genetic risk factors for common disorders, susceptibilities for behavioral characteristics) should at least be further explored prior to considering active prenatal screening for those conditions (45). For instance, starting one's life with a diagnosed condition that otherwise might have remained unnoticed over a lifetime may be beneficial in so far as such findings lead to better care. However, there may also be a potential for psychosocial harm (e.g. diminished self-esteem, parental over-protectiveness, and stigmatization) that needs to be taken into account $(45,62)$.

The idea that the welfare or autonomy interests of the future child may provide a reason for limiting the scope of prenatal testing is not uncontested. It has been argued that given a 'basic right of reproductive choice and parental autonomy, (...) obtaining a fetus's complete genetic profile should be the parents' choice' (63). There are two elements in this quote that require separate discussion: reproductive and parental autonomy. Starting with the latter, the claim that (prospective) parents have a right to their child's complete genetic profile seems to ignore that parental autonomy is rooted in parental responsibility. What the concept means is that parents are usually in the best position to see what is in their children's interests and that this is why professionals should normally respect the decisions that parents make on behalf of their children, including in situations where the child's interest is unclear. However, in cases where professionals have strong grounds for thinking that parental choices would be harmful, they do have a responsibility to protect the child they are treating. This limits the extent to which professionals should respect parental (non-)disclosure preferences (64). Parents can claim neither a 'right not-to-know' with regard to findings that are clearly beneficial (e.g. actionable childhood disorders) nor a 'right to know' with regard to findings at odds with the child's welfare or autonomy interests (non-actionable late-onset disorders).

But what about reproductive autonomy? Limiting the scope of prenatal screening so as to avoid findings that may harm the future child denies pregnant women the option of using that same information for a possible termination of pregnancy. Unlike the appeal to parental autonomy, this is a real dilemma. It is not entirely new although: in the specific context of prenatal diagnosis of neurogenetic disorders (such as Huntington disease), a form of 'conditional access' to testing (i.e. only for those who intend to ask for termination in case of a positive result) has been proposed as a possible solution (65, 66). However, this applies to targeted prenatal testing in affected families, where such pretest agreements can (to some extent) be meaningfully made. In the context of broad-scope prenatal screening, the only way out is to weigh the opposing interests. It would seem that the interest of the future child not to be sent into the world with a complete genome scan already done is the more weighty consideration here.

\section{Double purpose screening}

Broad-scope NGS-based screening may become the genomic equivalent of routine prenatal ultrasound. Similar to ultrasound, it will lead to identification of both untreatable abnormalities and conditions that enable adapted care or an adapted delivery setting. Increasingly, this will also include options for fetal therapy. Bianchi refers to this scenario as follows: 'Historically, the goal of prenatal diagnosis has been to provide an informed choice to prospective parents. We are now at a point where that goal can and should be expanded to incorporate genetic, genomic and transcriptomic data to develop new approaches to fetal treatment.' (67). But it would seem more appropriate to say that this further aim of opening up preventive and therapeutic options raises questions about parental and professional responsibility that cannot simply be accounted for under the autonomy paradigm. Also in this respect, broad-scope screening is like routine prenatal ultrasound, whose undirected character and irreducible double purpose have always challenged the normative framework. What has long been an exception may thus become the rule. How to deal with this tension? As the benefits for pregnant women and their future children are potentially large, it can be argued that we need a revised ethical framework that moves beyond the strict compartmentalization of autonomyand prevention-aimed screening without ignoring the ethical considerations behind this distinction (46). Clearly, a central element of this new ethical framework 
will have to be the relationship between the pregnant woman's reproductive autonomy on the one hand and (if she decides to carry the pregnancy to term) her responsibility for the future child on the other (68). This will need to be fine-tuned, taking account of medical data and variables regarding for instance the magnitude of harms to be prevented, the effectiveness as well as possible burdens and risks of (experimental) therapies, and maternal and future children's interests. This will also require a further determination of relevant professional responsibilities: to what extent should information about double purpose screening be non-directive? Especially with regard to conditions for which prenatal therapy would be possible, there is a risk of disproportionally subordinating the freedom and interests of the pregnant women to the potential interests of the future child (46).

\section{Conclusion}

The still narrow scope of prenatal screening for chromosomal abnormalities should not deceive us: the era of broad-scope genomic prenatal screening is already unfolding at the invasive testing stage. The next steps toward a non-invasive comprehensive fetal genome scan seem only limited by the current state of the technology and costs. While this makes it an urgent question what prenatal screening should be offered for and why, the current ethical framework is unable to answer this question. In view of the dynamics of the field, there is a need for a revised framework able to guide the broadening of the scope of prenatal screening in a way that focuses on providing meaningful reproductive choices, while respecting the informational interests of the future child, and acknowledging that broad-scope genomic prenatal screening will be like prenatal ultrasound in not easily fitting the distinction between autonomy and prevention. In the light of these challenges and the urgent need for further ethical reflection, it seems wise not for the time being to expand the scope of prenatal genomic screening beyond serious congenital and childhood-onset disorders $(24,46)$. Clearly, this is already a huge step beyond current aneuploidy screening that will require careful consideration of all relevant aspects, including the complementarity of screening at the prenatal and preconception stages (46). As carrier screening prior to pregnancy provides couples with more reproductive options and more time for reflection, this should be integrated in a broader debate about the future of reproductive (rather than only prenatal) screening.

\section{Acknowledgements}

The work of W. J. D. and G. d. W. for this review was part of the research project 'Widening scope of prenatal screening by non-invasive prenatal diagnostics (NIPD): Consequences for counseling, informed decision making, and screening policy', funded by the Netherlands Organization for Health Research and Development (ZonMw), grant nr. no: 209020003.

\section{Conflict of interest}

The authors have no conflicting interests.

\section{References}

1. Juth N, Munthe C. The ethics of screening in health care and medicine: serving society or serving the patient? Dordrecht; Heidelberg; London; New York, NY: Springer, 2012

2. Health Council of the Netherlands. Screening: between hope and hype. The Hague: Health Council of the Netherlands, 2008.

3. Savitz DA. How far can prenatal screening go in preventing birth defects? J Pediatr 2008: 152: 3-4.

4. Murray J, Cuckle H, Taylor G, Littlewood J, Hewison J. Screening for cystic fibrosis. Health Technol Assess (Winchester, England) 1999: 3 (i-iv): $1-104$.

5. Stein Z, Susser M, Guterman AV. Screening programme for prevention of Down's syndrome. Lancet 1973: 1: 305-310.

6. Clarke AJ. Prenatal screening. Paradigms and perspectives. In: Harper DS, Clarke AJ, eds. Genetics, society and clinical practice. Oxford: Bios Scientific Publishers, 1997: 119-140.

7. Parens E, Asch A. The disability rights critique of prenatal genetic testing. Reflections and Recommendations. Hastings Cent Rep 1999: 29 $\mathrm{S} 1-\mathrm{S} 22$.

8. Reinders JS. The future of the disabled in liberal society. An ethical analysis. Notre Dame: Notre Dame University Press, 2000.

9. Wilkinson S. Prenatal screening, reproductive choice, and public health. Bioethics 2015: 29: 26-35.

10. Ames AG, Metcalfe SA, Dalton Archibald A, Duncan RE, Emery J. Measuring informed choice in population-based reproductive genetic screening: a systematic review. Eur J Hum Genet 2015: 23: 8-21.

11. Health Council of the Netherlands. Prenatal screening: Down's syndrome, neural tube defects, routne-ultrasonography. The Hague: Health Council of the Netherlands, 2001

12. Malone FD, Canick JA, Ball RH et al. First-trimester or second-trimester screening, or both, for Down's syndrome. N Engl J Med 2005: 353: 2001-2011.

13. Eik-Nes SH. The 18-week fetal examination and detection of anomalies. Prenat Diagn 2010: 30: 624-630.

14. Mersy E, Smits LJ, van Winden LA et al. Noninvasive detection of fetal trisomy 21: systematic review and report of quality and outcomes of diagnostic accuracy studies performed between 1997 and 2012. Hum Reprod Update 2013: 19: 318-329.

15. Benn P, Cuckle H, Pergament E. Non-invasive prenatal testing for aneuploidy: current status and future prospects. Ultrasound Obstet Gynecol 2013: 42: 15-33.

16. Norton ME, Jacobsson B, Swamy GK et al. Cell-free DNA analysis for noninvasive examination of trisomy. N Engl J Med 2015: 372: 1589-1597

17. Chitty LS, Hill M, White H, Wright D, Morris S. Noninvasive prenatal testing for aneuploidy-ready for prime time? Am J Obstet Gynecol 2012: 206: 269-275.

18. Wapner RJ, Levy B. The impact of new genomic technologies in reproductive medicine. Discov Med 2014: 17: 313-318.

19. Stark Z, Gillam L, Walker SP, McGillivray G. Ethical controversies in prenatal microarray. Curr Opin Obstet Gynecol 2013: 25: 133-137.

20. American College of Obstetricians and Gynecologists. Committee Opinion No. 581: the use of chromosomal microarray analysis in prenatal diagnosis. Obstet Gynecol 2013: 122: 1374-1377.

21. van Schendel RV, Kleinveld JH, Dondorp WJ et al. Attitudes of pregnant women and male partners towards non-invasive prenatal testing and widening the scope of prenatal screening. Eur J Hum Genet 2014: 22: $1345-1350$.

22. van den Heuvel A, Chitty L, Dormandy E et al. Will the introduction of non-invasive prenatal diagnostic testing erode informed choices? An experimental study of health care professionals. Patient Educ Couns 2010: 78: 24-28

23. Newson AJ. Ethical aspects arising from non-invasive fetal diagnosis. Semin Fetal Neonatal Med 2008: 13: 103-108.

24. Dondorp W, de Wert G, Bombard Y et al. Non-invasive prenatal testing for aneuploidy and beyond: challenges of responsible innovation in prenatal screening. Eur J Hum Genet 2015. doi: 10.1038/ejhg.2015.57.

25. Lichtenbelt KD, Diemel BD, Koster MP et al. Detection of fetal chromosomal anomalies: does nuchal translucency measurement have added value in the era of non-invasive prenatal testing? Prenat Diagn 2015: 35 : $663-668$.

26. Susman MR, Amor DJ, Muggli E, Jaques AM, Halliday J. Using population-based data to predict the impact of introducing noninvasive prenatal diagnosis for Down syndrome. Genet Med 2010: 12: 298-303. 


\section{Genomic futures of prenatal screening}

27. Lau TK, Jiang FM, Stevenson RJ et al. Secondary findings from non-invasive prenatal testing for common fetal aneuploidies by whole genome sequencing as a clinical service. Prenat Diagn 2013: 33 : 602-608.

28. Mazloom AR, Dzakula Z, Oeth P et al. Noninvasive prenatal detection of sex chromosomal aneuploidies by sequencing circulating cell-free DNA from maternal plasma. Prenat Diagn 2013: 33: 591-597.

29. Vora NL, O'Brien BM. Noninvasive prenatal testing for microdeletion syndromes and expanded trisomies: proceed with caution. Obstet Gynecol 2014: 123: 1097-1099.

30. Wapner RJ, Babiarz JE, Levy B et al. Expanding the scope of noninvasive prenatal testing: detection of fetal microdeletion syndromes. Am J Obstet Gynecol 2015: 212: 332.e331-332.e339.

31. Ogilvie CM, Yaron Y, Beaudet AL. Current controversies in prenatal diagnosis 3: For prenatal diagnosis, should we offer less or more than metaphase karyotyping? Prenat Diagn 2009: 29: 11-14.

32. de Jong A, Dondorp WJ, Timmermans DR, van Lith JM, de Wert GM. Rapid aneuploidy detection or karyotyping? Ethical reflection. Eur J Hum Genet 2011: 19: 1020-1025.

33. Leung WC, Lau ET, Lau WL et al. Rapid aneuploidy testing (knowing less) versus traditional karyotyping (knowing more) for advanced maternal age: what would be missed, who should decide? Hong Kong Med J 2008: 14: 6-13.

34. Callaway JL, Shaffer LG, Chitty LS, Rosenfeld JA, Croll JA. The clinical utility of microarray technologies applied to prenatal cytogenetics in the presence of a normal conventional karyotype: a review of the literature. Prenat Diagn 2013: 33: 1119-1123.

35. Vanakker O, Vilain C, Janssens $\mathrm{K}$ et al. Implementation of genomic arrays in prenatal diagnosis: the Belgian approach to meet the challenges. Eur J Med Genet 2014: 57: 151-156.

36. Vetro A, Bouman K, Hastings $\mathrm{R}$ et al. The introduction of arrays in prenatal diagnosis: a special challenge. Hum Mutat 2012: 33: 923-929.

37. McGillivray G, Rosenfeld JA, McKinlay Gardner RJ, Gillam LH. Genetic counselling and ethical issues with chromosome microarray analysis in prenatal testing. Prenat Diagn 2012: 32: 389-395.

38. de Jong A, Dondorp WJ, Macville MV, de Die-Smulders CE, van Lith JM, de Wert GM. Microarrays as a diagnostic tool in prenatal screening strategies: ethical reflection. Hum Genet 2014: 133: 163-172.

39. Wolf SM, Annas GJ, Elias S. Point-counterpoint. Patient autonomy and incidental findings in clinical genomics. Science 2013: 340: 1049-1050.

40. van der Steen SL, Diderich KE, Riedijk SR et al. Pregnant couples at increased risk for common aneuploidies choose maximal information from invasive genetic testing. Clin Genet 2015: 88: 25-31.

41. Hewison J. Psychological aspects of individualized choice and reproductive autonomy in prenatal screening. Bioethics 2015: 29: 9-18.

42. de Jong A, Dondorp WJ, Frints SG, de Die-Smulders CE, de Wert GM. Advances in prenatal screening: the ethical dimension. Nat Rev Genet 2011: 12: 657-663.

43. Lo YM, Chan KC, Sun H et al. Maternal plasma DNA sequencing reveals the genome-wide genetic and mutational profile of the fetus. Sci Transl Med 2010: 2: 61ra91.

44. Kitzman JO, Snyder MW, Ventura M et al. Noninvasive whole-genome sequencing of a human fetus. Sci Transl Med 2012: 4: 137ra176.

45. Donley G, Hull SC, Berkman BE. Prenatal whole genome sequencing: just because we can, should we? Hastings Cent Rep 2012: 42: 28-40.

46. de Jong A, de Wert GM. Prenatal screening: an ethical agenda for the near future. Bioethics 2015: 29: 46-55.
47. Walser SA, Kellom KS, Palmer SC, Bernhardt BA. Comparing genetic counselor's and patient's perceptions of needs in prenatal chromosomal microarray testing. Prenat Diagn 2015. doi: 10.1002/pd.4624.

48. Munthe C. A new ethical landscape of prenatal testing: individualizing choice to serve autonomy and promote public health: a radical proposal. Bioethics 2015: 29: 36-45.

49. Gavaghan C. Defending the genetic supermarket. Law and ethics of selecting the next generation. London: Routledge, 2007.

50. Schwartz B. The paradox of choice. Why more is less. New York, NY: HarperCollins Publishers, 2004.

51. Dworkin G. The theory and practice of autonomy. Cambridge: CUP, 1988.

52. Berg JS, Khoury MJ, Evans JP. Deploying whole genome sequencing in clinical practice and public health: meeting the challenge one bin at a time. Genet Med 2011: 13: 499-504.

53. Botkin JR. Fetal privacy and confidentiality. Hastings Cent Rep 1995: 25: 32-39.

54. Borry P, Evers-Kiebooms G, Cornel MC, Clarke A, Dierickx K. Genetic testing in asymptomatic minors: background considerations towards ESHG Recommendations. Eur J Hum Genet 2009: 17: 711-719.

55. American Academy of Pediatrics. Ethical and policy issues in genetic testing and screening of children. Pediatrics 2013: 131: 620-622.

56. Feinberg J. The child's right to an open future. In: Aiken W, LaFolette H, eds. Whose child? Children's rights, parental authority and state power. Totowa, NJ: Littlefield, Adams \& Co, 1980: 124-153.

57. Millum J. The foundation of the child's right to an open future. J Soc Philos 2014: 45: 522-538.

58. Kopelman LM. Using the Best Interests Standard to decide whether to test children for untreatable, late-onset genetic diseases. J Med Philos 2007: 32: 375-394.

59. Deans Z, Clarke AJ, Newson AJ. For your interest? The ethical acceptability of using non-invasive prenatal testing to test 'purely for information'. Bioethics 2015: 29: 19-25.

60. Dondorp WJ, de Wert GM. The 'thousand-dollar genome': an ethical exploration. Eur J Hum Genet 2013: 21 (Suppl. 1): S6-S26.

61. Netzer C, Schmitz D, Henn W. To know or not to know the genomic sequence of a fetus. Nat Rev Genet 2012: 13: 676-677.

62. Clarke A. The genetic testing of children. Working Party of the Clinical Genetics Society (UK). J Med Genet 1994: 31: 785-797.

63. Yurkiewicz IR, Korf BR, Lehmann LS. Prenatal whole-genome sequencing--is the quest to know a fetus's future ethical? N Engl J Med 2014: 370: 195-197.

64. Dondorp W, Sikkema-Raddatz B, de Die-Smulders C, de Wert G. Arrays in postnatal and prenatal diagnosis: an exploration of the ethics of consent. Hum Mutat 2012: 33: 916-922.

65. MacLeod R, Tibben A, Frontali M et al. Recommendations for the predictive genetic test in Huntington's disease. Clin Genet 2013: 83: $221-231$.

66. De Wert G. Ethical aspects of prenatal testing and preimplantation genetic diagnosis for late-onset neurogenetic disorders: the case of Huntington's disease. In: Evers-Kiebooms G, Zoeteweij M, Harper P, eds. Prenatal testing for late-onset neurogenetic diseases. Oxford: BIOS Scientific Publishers Ltd, 2002: 129-157.

67. Bianchi DW. From prenatal genomic diagnosis to fetal personalized medicine: progress and challenges. Nat Med 2012: 18: 1041-1051.

68. Murray TH. Moral obligations to the not-yet born: the fetus as patient. Clin Perinatol 1987: 14: 329-343. 